Environment Conservation Journal 19 (3)73-75, 2018

ISSN 0972-3099 (Print) 2278-5124 (Online)

Abstracted and Indexed

\title{
Role of Adhatoda vasaca in management of respiratory disorders
}

\author{
Rani Jyoti ${ }^{1}$ 凶, Pandey Shikha ${ }^{2}$, Kumavat Vinod Bihari ${ }^{3}$ and Sharma Uttam Kumar ${ }^{4}$
}

Received: 21.05 .2018

Revised: 28.07 .2018

Accepted: 14.11.2018

\begin{abstract}
Medicinal plants have been subjects of man's curiosity since time immemorial. Approximately $80 \%$ of the people in the world's developing countries rely on traditional medicines for their primary health care needs.Adhatoda vasaca is an evergreen shrub distributed from the punjab in the north and Bengal and Assam in the south-east to singapore.The plant is valued for containing bronchodilator alkaloid, mainly vasicine.It is well known in ayurveda by its sanskrit name vasaka and commonly known as adusa.
\end{abstract}

Key words: Vasa, Vasicine, bronchitis, Adhatoda vasaca

\section{Introduction}

Today there is industrialized \& commercialized environment is around us.The incidence of several respiratory disorders are gaining concern day by day.Air pollution is the $6^{\text {th }}$ leading cause of respiratory ailments.Ayurvedic classics have a unique wealth of medicinal plants \&vast traditional knowledge of herbal medicines for cure of various diseases.Adhatoda vasica commonly known as malabar nut belongs to the medicinal family Acanthaceae,is an evergreen shrub.The shrub is the source of drug-vasaca,well known in indigenous systems of medicines for its beneficial effects,predominantly in bronchitis.The leaves,flowers,fruits and roots are extensively used for treating cold,cough,chronic bronchitis ,asthma and also used as expectorant( Sharma PC ).It is licensed drug and is mentioned in the India pharmacopia(Pharmacopia of india,1966).The drug is employed in different forms such as fresh juice,decoction,powder and also given as alcoholic extract or liquid extract or syrup.In Ayurvedic preparation,vasa leaf juice(vasa swaras) is incorporated in more than 20 formulations'(The frequent use of adhatoda vasaca has resulted in its inclusion in WHO manual-The use of traditional medicine in primary health care ( WHO-primary

Author's Address

${ }^{1,2 \& 4}$ Department of panchkarma,Gurukul Campus,UAU Haridwar

${ }^{3}$ Regional research Institute, CCRAS, Jaipur

E-mail.:druksm27@gmail.com health care).

Prevalance of respiratory disorders

According to centre for disease control (CDC), COPD is $4^{\text {th }}$ leading cause of death. Its prevalence increased with age. Disease of lung and airways are the most common cause of illness in children in developing countries. In worldwide, there tends to be more asthma and allergy in west and infections disease in east.Respiratory disease responsible for approximately 6.8 million emergency visits.one in seven individual are affected by Chronic lung disease,COPD,Asthma,bronchitis etc.A survey by Govt. of India has reported 2.63 Crore Indians suffering from acute respiratory disease due to air pollution-both household and environmental.The central pollution board has reported maximum no. of deaths due to respiratory ailments in West bengal followed by Odisha,Andhra pradesh,Uttar pradesh,Delhi(Chouhan, 2013).

\section{Phytochemical studies}

The main constituents of adhatoda vasica are pyroquinazolone alkaloids viz. vasicine \&vasicinone.Vasicine at low concentration, induced relaxation of tracheal muscle.At high concentration,Vasicine offered significant protection against histamine induced bronchospasm .Vasicinone,the auto-oxidation product of vasicine (Brain and thapa 1981,Chowdhari and Hirani1981) has been reported cause bronchodilatory effects both in vitro and vivo. Apart from it leaf with vasicol, adhatonine, vasicinone, peganine, betaine, 
Table 1. Showing Botanical classification of Vasaca adhatoda

\begin{tabular}{|l|l|}
\hline Division & Angiosperms \\
\hline Class & Eudicots \\
\hline Order & Lamiales \\
\hline Family & Acanthaceae \\
\hline Genus & Vasaca \\
\hline Species & $\begin{array}{l}\text { Vasaca adhatoda(Myanmar } \\
\text { Medicinal plant database) }\end{array}$ \\
\hline
\end{tabular}

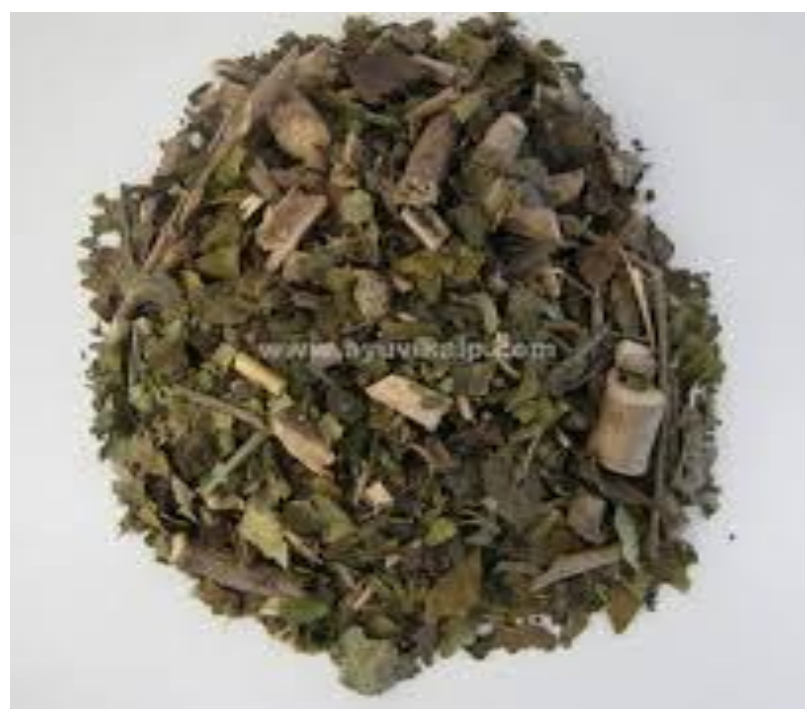

(a) Dry vasa

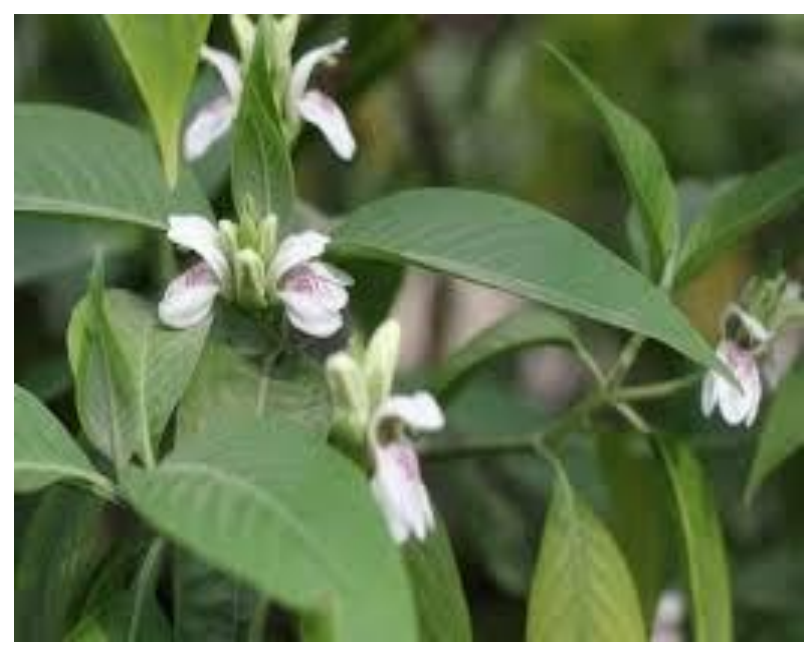

(b) Fresh vasa plant

Fig 1. (a and b) Showing dry and fresh Vasa Plant steroids and alkanes.It also contains vitamin C, saponins,flavonoids as well as steroids and fatty acids.Essential oils of leaves of adhatoda vasaca also known to contain ketones, terpene \& phenolic ether (Gupta).

\section{Compound Formulations}

Apart from above analytical methods, a study was conducted to identify a method which extracts similar quality of total alkaloid obtained by traditional method.In this experiment,juice was prepared by four methods.Ist,traditional bolus methods (put paka vidhi) was used,where as $2^{\text {nd }}$ method employed was steaming of leaves.In $3^{\text {rd }}$ method, vasa swaras was prepared by manual way and in $4^{\text {th }}$ using grinder.The study revealed that juice (swaras) ptepared by traditional putpaka vidhi method contained highest amount of total alkaloids $5.93 \mathrm{mg} / \mathrm{ml} \&$ vasicine $5.64 \mathrm{mg} / \mathrm{ml}$ of juice.In the modified method,total alkaloid content was 4.05 $\mathrm{mg} / \mathrm{dl} \&$ vasicine content $3.4 \mathrm{mg} / \mathrm{ml}$ that is less that of traditional method.so different formulation is mentioned in ayurvedic classics (soni S) Vasa Kwath,Vasa swaras,Vasa ghrita,vasa avleha,vasa ghrita,vasa arishta.

\section{Role of treatment of respiratory disorders}

Respiratory disorders are different like bronchitis, asthma, COPD, allergic respiratory diseases, cough, tuberculosis etc.

Cough: It is body's main method to remove dust, mucosa, saliva, and other debris from lungs.Inability to cough can lead to infection.In adhatoda vasaca, identified for its antituusive activity.It has been proved as effective as codeine on mechanically or electrically and irritant aerosols induced coughing. There was $67 \%$ cough supression with adhatoda vasaca which was comparable with codeine 62\% (Dhuley, 1999).

Chronic Bronchitis: Any irritant reaching bronchi $\&$ bronchioles will stimulate increased secretions of mucous.In chronic bronchitis, air passages becomes clogged with mucous \& leads to persistant cough. COPD (Chronic obstructive pulmonary disease): COPD is lung disease characterized by chronic obstruction of lung airflow that interferes with normal breathing. And not fully reversible.In 1959 ,ist study was reported to claim bronchodilation activity of vasicinone.Along with vasicinone,hiterto,( a unknown alkaloid from vasa) showed pronounced protection against allerged induced bronchial obstruction.Vasicine is also claimed to have bronchodilator activity.The oral administration of alkaloid named hexahydroazepino(RLX) ( a molecule of alkaloid vasicine by chemical modification) inhibit antigen induced mast cell degranulation \& histamine secretion from 
target tissue that leads to clear the obstruction. (Tohri, 2000)

Asthma: Periodic constriction of bronchi \& bronchioles make it more difficult to breathe.A clinical study was conducted to assess the effect of syrup prepared from vasa with 2 two different types of dose of vasa, namely aqueous extract (swaras) and heated extract (kwath). Both formulation showed significant reduction in symptomps of asthma observed in patient and certain hematological parameters.But more significant decrease noted with aqueous extract (swaras) (Gupta A,2009). A Compound "pentalopa-04", where vasa are one of ingredient prevents lung injury \& inflammatory changes proving antihistametic activity. Furthur more, Sharma and Atal have prove efficacy of vasa against allerged induced bronchial obstruction (Rao, ).

Anti-Tubercular activity: In an experiment, benzylamines, bromhexine and ambroxol, semi synthetic derivatives of vasicine, have a $\mathrm{PH}-$ dependent growth inhibitory effect on M.tuberculosis.These compounds found to be concentrated in macrophages, in vitro study,along this effect enhancement of lysozyme levels in bronchial secretion \& possibly clearance of bacilliladder mucus from cavities \& bronchi observed suggesting potentially useful adjuvant therapy of tuberculosis(Gupta, 2001).

\section{Results and Discussion}

Adhatoda vasaca ,a medicinal herb have habitat in tropical and Subtropical regions.Various analytical methods have been adopted for identification and isolation of chemical constituents.Adhatoda vasaca is important natural agent for many medical illness.It has anti-inflammatory action on respiratory tract and effective in respiratory tract infection.The alkaloid vasicinone \& vasicine have potent bronchodilator and anti allergic activity.So it is effective in acute conditions of asthma.it has been proved for antitussive activity as effective as codeine in irritant aerosol induced cough model.Adhatoda vasaca is effective in acute upper respiratory tract infection as well.Aqueous extract of adhatoda vasaca is found to be effective in growth inhibition of M.tuberculosis. Reseacher have revealed the antigen $85 \mathrm{C}$ of M.tuberculosis as most potent biological target of vasicine.Both these findings can help to develop new therapeutic drug to control global threat of Tuberculosis.Many more studies proved the antioxidant \& free medical scavenging potential of adhatoda vasaca .Due to its antioxidant activity,Adhatoda vasaca may effective in anti-cytotoxic effect.An herbal tea of an expectorant action was prepared with adhoda vasaca leaves.The prepared herbal base tea is proposed as a good expectorant.Along with vasicine ,hitherto, (a unknown alkaloid from vasa) showed pronounced protection against allerged induced bronchial obstruction.so it found effective in COPD.

\section{Conclusion}

Adhatoda vasaca promotes curing of both upper \& lower respiratory infection.It has remarkable activity against cough, asthma, bronchitis.It act as bronchodilator, anti-tussive, have antiallergic activity, effective in respiratory ailments of infants and adults.

\section{References}

Chauhan C., 2013. Deaths from respiratory illness on rise, Hindustan times, new Delhi.

Dhuley J.N., 1999. Antitussive effect of AV extract on mechanical or chemical stimulation induced coughing in animals, 67:361-365.

Gupta A., Prajapati P.K., Choudhary A.K., 2009. A comparative study of effects of vasa avaleha preparation with vasa svaras \& vasa kwath in tamaka shwasa, anc science life, 28:288.

Gupta R.,Thakur B., Singh P.,Singh H.B, 2001. Anti T.B, activity of selected medicinal plants against $\boldsymbol{M D R}: 809-813$.

Gupta U.P. , and Sharma M.L. , Pharmacological investigation of vasicine and vasicinone ,alkaloid of adhatoda vasaca, Myanmar Medicinal plant database.

Rao S.D., Jayarang I.A.,Jay .R., Anti asthmatic role of pentapale 04,herbal formulation against on induced ling damage.

Sharma P.C., and Yelne M.B., Database on medicine plant in ayurveda, $\boldsymbol{C C R A S , ~ 1 : ~ 4 9 6 - 5 0 9 . ~}$

Soni S., Anandgiwala S., Inter G., Rajan M., Validation of different methods of preparation of vasa leaf juice by quantification of total alkaloids.

Tohri R.K., Zustu, U., 2000. Mechanism of 12-hexahydroazepino,a novel bronchodilator, Indian pharmacology, 44:75-81.

WHO. Primary health care, A manual of health works in south-east asia, 19:1-2. 